tions:- "We have brilliant colouring in green fields, blue sky, purple sea, and cliffs of red marl or white chalk. Relief is present, if necessary, in the mild stimulation of black ploughed fields, grey cloud, or bare and craggy mountain-top. The snowy summits of the Alps shine with dazzling whiteness, and the fleecy clouds are tinged with gold or silver. Curved form is found in sweeping dale and sloping hillside. Variety is given us in all the prospect. Flat and monotonous fields fatigue us. The desert with its hot level expanse of grey sand, sweltering and blinking in the full glare of a tropical sun, is our ideal of utter dulness. The unbroken green of Western prairies is scarcely lese tiring. The sea without a sail, as seen from mid-ocean, is miserably dull. A whale, a porpoise, or even a good foam. ing gale, is hailed as a grateful variety. When in search of æsthetic pleasure we seek the interchange of hill and dale, river and waterfall, castle and abbey, green valley and iceclad height. We climb downs for the extended view, spend our holiday at the seaside for the sake of cliffs and water, or ransack Iceland, Ceylon, or Colorado in search of picturesque novelty in geyser and volcano, palm and treefern, cañ $n$, and lava plain. Symmetry we alone reject, because we have learnt to associate that with the puny works of man, or where we find it in the outer world to expect it only in detail. Our notions of sublimity require that in her grandest achievements Nature should not be tied down to rule and plummet."

1 Treatise on the Lavos relating to the Pollution and Obstruction of Watercourses; together with a brief Summary of the various Sources of River Pollution. By CLEMent Higgins, M.A., F.C.S., Barrister-at-Law, formerly Dewonstrator of Chemistry at King's College, London. London: Stevens and Haynes. 1877.

THe Rivere Pollution Prevention Act of 1866 was, as we pointed out at the time of its introduction, a weak attempt to deal with a flagrant and increasing evil. The medical profession was disappointed that so little was done after so much of preliminary inquiry and expense. The basis of a sound measure had been provided, after years of study, by the labour of two successive Royal Cornmissions. Every interest involved had been considered and, with wrifling exceptions, allowed for, and remedies which would have been effectual suggested, yet the Government Bill, when it appeared, ignored nearly all these labours, and hedged the few enactments which it contained so carefully, and stated them so vaguely, that little real good conld be expected from it. Weak as it was, it was diluted still further in committee, so that as it now stands it is one of the feeblest of Acts of Parliament.

With reference to this and to all other Acts affecting riparian rights and duties, Mr. Higgins's book will be found a valuable guide. He has given a faithful and intelligible account of the present state of the law as far as it is possible to do so, and his scientific training has enabled him to discuss and comment upon many points that could not have been dealt with by the mere lawyer. The work is well written and well arranged, and has a good index; and it will be extremely useful to the very numerous class of persons interested in the question.

Anthracen: its Constitution, Properties, Manufacture, and Derivatives, including Artificial Alizarin, Anthrapurpurin, \&c., with their Applications in Dyeing and Printing By G. AUERBACH. 'Iranslated and edited from the revised Manuscript of the Author, by WILLIAM CRookes, F.R.S., \&c. \&c. Longmans and Co. 1877.

Works like this, devoted to some single chapter in the history of Applied Chemistry, illustrate in a striking manner the wonderful progress which the science has made of late years, and the great national and even political im portance of scientific research. Anthracen was first obtained by Dumas and Laurent, in 1832, from the heavier portion of coal-tar. For more than forty years the discovery had no practical importance, but at last two German chemists, Graebe and Liebermann, showed that anthracen could by a series of operations be made to yield alizarin, the colouring-matter of madder. Applications of this new discovery were soon made. Artificial alizarin is now an important article in commerce, and we are no longer dependent upon a foreign country for our supply of one of the most important of dye-stuffs. The intricate chemistry of anthracen and the compounds allied to it is expounded with great lucidity in the work before us, and the difficulty of the task accomplished may be guessed from the fact that no less than twenty-one pages are devoted to the bibliography of the subject. A good practical account of the manufacturing processes which are and have been in use is also given, and altogether the work may be commended as a most excellent theoretical and practical monograph. As the translator and editor is $\mathrm{Mr}$. Crookes, it is almost unnecessary to say that the English edition is all that could be wished.

Zoology. By ANDrew Wrlson, Ph.D. One of Chambers's Elementary Science Manuals. Edinburgh: Chambers and Co. 1877.

THis little book of 152 pages has been written on the principle that to know a few types accurately is much more serviceable to the beginner than a wider range of unconnected facts relating to a large number of animals. The types here taken are the amceba, the bydra, the sea anemone, the anodon, the lobster, and the frog. We think one mammal, as the cat, might have been added. The descriptions of the animals and their organs are remarkably clear, and will, we think, be found perfectly intelligible by an unlearned but attentive reader. The letter-press is illustrated by fifty drawings. Dr. Wilson, in speaking of the preservation of anemones in aquaria, remarks that one famous anemone, now in the possession of Dr. M'Bain, of Trinity, near Edinburgh (Actinia mesembryanthemum), first possessed by Sir John Dalzell in 1828, produced 276 young in six years. This animal, known as "granny," is still alive, and has occasionally produced young in large numbers. Between 1828 and 1851 "granny" produced 344 yonng anemones, and in 1857 in one night gave birth to 240 young. Dr. Wilson's little manual very thoroughly fulfils its object.

\section{A NEW METHOD FOR THE QUANTITATIVE DETERMINATION OF SUGAR IN BLOOD.}

\author{
BY F. W. PAVY, F.R.S.
}

DR. PAvY read a paper on Thursday, the 14th inst., before the Ryal Society, in which he described minutely his new method for the quantitative determination of glucose, and its application to physiological relations of sugar in the animal system. The accurate results which Dr. Pavy has succeeded in obtaining by means of his new gravimetric process of analysis, and the importance of the subject itself, are such as will tend to advance materially our $k n$ wledge, and hence will substantiate and extend the position with regard to the treatment and pathology of diabetes.

The paper consisted chiefly of a description of the method which the author adopted for accurately ascertaining the amount of sugar in the blood of animals, and formed the prelude to on $\theta$ which was read on Thursday, the 21st

1 Abstract of paper read at the Royal Society, Juae 14th. 
inst., in which Dr. Pavy gave the results obtained by the application of his method as follows:-1. The natural state of the blood. 2. The comparative state of arterial and venous blood. 3. The sp ntaneous change ensuing in blood after its removal from the system.

Before describing his own gravimetric system Dr. Pavy proceeded to criticise Bernard's new volumetric process, which bas been described fully in recent issues of the Comptes Rendus. This method the author proved to be not only devoid of precision as a quantitative analytical process, but as in itself calculated to give rise to fallacious results, inasmuch as keeping the subnxide of copper dissolved by means of organic matter was fundamentally wrong. The entire system was based on errors, and the results were necessarily incorrect; two of these errors the author dealt with somewhat in detail. The first was in the assumption that the volume of trial liquid corresponds in c.c. with four-fifths of their weigbts in grammes of the mixture of sulphate of soda and blood. In practice it was found that the actual relation between the volume of liquid obtained and the weight of the mixture employed must vary in each individual case, according to the solid matter existing in the particular specimen of blood and the loss of liquid by evaporation during the separation of the congulum by heat. The other error in Bernard's method arose from the influence which organic matter exerted in preventing the deposition of suboxide. The large addition of potash which is employed in this process-viz., from 20 to 25 cubic centimetres of a concentrated solution to one c.c. of the copper test-acts upon some one or other of the organic principles left in the liquid obtained from the blood, and prevents the deposition of suboxide of copper.

The anthor then proceeded to describe his own new gravimetric process, in which he adopts the use of the galvanic battery for effecting the deposition of copper which has been reduced by the sugar in a form to be susceptible of weighing. The details of this method are, shortly, as follows:-

A certain volume of blood-about 20 c.c. forms a convenient quantity-is taken for analysis, and first mixed with 40 grammes of sulphate of sola; the whole must be subjected to weighing in detail, so that the precise weight of the blood taken may be known. To this mixture, contained in a beaker of about 200 c.c. capacity, about 30 c.c. of hot concentrated solution of sulphate of soda are added, and the whole contents heated until a coagulum is formed.

Filtration is then performed, and the coagulum thoroughly washed, so that all traces of sugar may be removed. The liquid thus obtained, from having been run and squeezed through muslin, is slightly turbid, and must be boiled again and filtered through paper to render it perfectly clear. It is now ready for the application of the copper test. Being brought to a state of ebullition, about 10 c.c. of the potassiotartrate of copper solution, or sufficient to secure that the test liquid is left in excess, are added, and brisk boiling continued for a minute, but not longer. In this way a reduction of the oxide to the suboxide of copper is effected by the action of the sugar present in the solution.

The liquid is then filtered through a plug of asbestos, or, what is better, glass wool. The suboxide, having been collected and washed from excess of the copper test liquid, is next dissolved by a few drops of nitric acid, a small quantity of peroxide of hydrogen having been previously added in order to effect oxidation and consequent ready solution.

The copper present in the liquid is now deposited by the agency of galvanism. The positive pole of the battery is formed by a platinum spiral coil, round which and forming the negative pole is a cylinder of platinum foil; upon this the copper is slowly deposited in a pure metallic form. This operation is continued until the appropriate test shows that the whole of the copper bas been thrown down. The period ordinarily required to effect this does not exceed 24 hours.

The platinum cylinder is next removed, and instantly plunged first into distilled water, and then into alcobol. After drying in a water oven it is ready for weighing; the difference in the weight of the cylinder before and af ter the operation gives the amount of copper deposited.

The battery used is a modification of Fuller's mercury bichromate battery, and has been selected on account of the constancy of its action.
From the amount of copper deposited, that of the sugars existing in the blood analysed may be accorately calculated. Five atoms of the cupric oxide of the test solution are reduced by 1 atom of glucose; it follows that 317 parts of copper represent the equivalent of one part of glucose, or the relation stands as 1 of copper to 0.5678 of glucose. Therefore, to ascertain the amount of sugar, the weight of the copper has to be multiplied by 0.5678 . This application of the copper test solution yields a gravimetric instead of a volumetric process of analysis, and one which has no uncertainty belonging to it. There is nothing for the mind to decide, and no opportunity for error of judgment, as may be the case to a slight extent where a gradual fading of colour-as in the volumetric process-has to be watched until the attainment of a proper point of the decolouration has been effected.

The accuracy and reliability of the foregoing process are strongly supported by the uniformity in the results obtained from a large number of experiments. Compared with the results yielded by this gravimetric process, those obtained by Bernard present the greatest discordancy. The figures he gives are invariably too high, and there is no intelligible relation in the differences noticeable, suggesting that there is something radically wrong in taking decolouration without precipitation of suboxide as a means of estimating the amount of sugar. Dr. Pavy supports tbis assertion by the conclusions derived from a large number of experiments.

\section{ST. ANDREWS GRADUATES' ASSOCIATION.}

THE ninth anniversary session of the Association was beld at the Westminster Palace Hotel, on Thursday, Juno 28th. Most interesting and instructive two hours were spent in Westminster Abbey, under the kind guidance of the Very Rev. the Dean, Lord Rector of St. Andrews. At the dinner in the evening, Dr. Lush, M.P., was in the chair, and was supported by Lord Gordon, Mr. Kuight, M.P., Mr. Ramsay, M.P., Prof. Smyth, M.P., Mr. Walter James, M.P., Mr. Rowley Hill, M.P., Dr. Cameron, M.P., Dr. Mitchell, Dr. Bucknill, Dr. Crichton Browne, Mr. Balfour Browne, Dr. Richardson, F.R.S., Rev. Dr. Rogere, Dr. Paul, Dr. Day of Stafford, Dr. Cholmeley, Dr. Kesteven, Dr. Weir of Mal. vern, Dr. MacEwen of Chester, Dr. Griffith, of Portmadoc, Dr. Cleveden, Dr. Wiltshire, Dr. Mott, Dr. Sedgwick, and many other London and country graduates. Dr. Lyon Playfair, M.P., was, to his great regret, prevented attending by his Parliamentary duties. Dr. Paul was presented with a handsome claret-jug and goblets, for his services as treasurer since the foundation of the Association. A very cordial vote of thanks to the Dean of Westminster was passed, and the hearty congratulation of the Association was offered to Dr. Richardson, F.R.S., on the recognition of his services to literature and the University by the conferring on him the degree of LL.D. of St. Andrews. The following members were elected as the executive for the year 1877-8:-Dr. Richardson, Prrsident of Council ; Dr. Paul, Honorary Treasurer; Dr. Sedg wick, Honorary Secretary. Council: Drs. Cholmeley, Christie. Cleveland, Crosby, H. Diy, Dudfield, Griffith, Griffiths, Holman, Lawrence, Lush, M.P., Macintyre, Mr. Menzies, Prof. Pettigrew, Dr. Julius Pollock, Rev. Dr. Rogers, Drs. Joseph Rigers, Lawes Rogers, Cooper Rose, Royston, Scott, Seaton, Whitmore, Willett, Duckworth Williams, Rbys Williams, Wiltshire, George Bird, Falls, Surg.-Major Franklin, Drs. Mortimer Granville, Kesteven, Charles Mott, Bransby Roberts, Stocker, Weir.

Death from Chloroform.-A death took place recently at Mercer's Hospital, Dublin, from the inbalation of chloroform. The patient, who suffered from disease of the knee, had chloroform administered for some trifling operation, but, in a very short time alarming symptoms presented themselves, death taking place in a few minutes. A post-mortem examination, conducted by Dr Egan, showed that fatty degeneration of the heart was present. It may be mentioned that Mercer's Hospital was the institution to which the late Dr. Jobn Morgan was attached as one of the visiting surgeons, and whose exertions in the cause of ether versus chloroform as an anæsthetic are well known. 